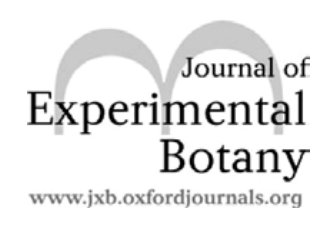

\title{
Specification of floral organs in Arabidopsis
}

\author{
Frank Wellmer ${ }^{1, *}$, Emmanuelle Graciet ${ }^{1,2}$ and José Luis Riechmann ${ }^{3,4, *}$ \\ ${ }^{1}$ Smurfit Institute of Genetics, Trinity College Dublin, Dublin, Ireland \\ 2 Department of Biology, National University of Ireland Maynooth, Ireland \\ ${ }^{3}$ Center for Research in Agricultural Genomics (CRAG) CSIC-IRTA-UAB-UB, Barcelona, Spain \\ ${ }^{4}$ Institució Catalana de Recerca i Estudis Avançats (ICREA), Barcelona, Spain \\ *To whom correspondence should be addressed. E-mail: wellmerf@tcd.ie or joseluis.riechmann@cragenomica.es
}

Received 31 August 2013; Revised 17 October 2013; Accepted 18 October 2013

\begin{abstract}
Floral organs are specified by the activities of a small group of transcriptional regulators, the floral organ identity factors. Extensive genetic and molecular analyses have shown that these proteins act as master regulators of flower development, and function not only in organ identity determination but also during organ morphogenesis. Although it is now well established that these transcription factors act in higher order protein complexes in the regulation of transcription, the gene expression programmes controlled by them have remained largely elusive. Only recently, detailed insights into their functions have been obtained through the combination of a wide range of experimental methods, including transcriptomic and proteomic approaches. Here, we review the progress that has been made in the characterization of the floral organ identity factors from the main model plant Arabidopsis thaliana, and we discuss what is known about the processes acting downstream of these regulators. We further outline open questions, which we believe need to be addressed to obtain a more complete view of the molecular processes that govern floral organ development and specification.
\end{abstract}

Key words: Arabidopsis, floral organ identity factors, flower development, homeotic mutants

\section{Introduction}

Arabidopsis flowers are composed of four different types of floral organs, which are arranged in concentric circles or whorls. From the outside (the first whorl) to the centre (the fourth whorl) they are sepals, petals, stamens, and carpels (Fig. 1A). Floral organs are specified by a small group of regulatory genes, the so-called floral organ identity genes, which were identified based on mutants whose flowers exhibited homeotic organ transformations, namely the replacement of (at least) one type of floral organ by another (Krizek and Fletcher, 2005; Causier et al., 2010; Bowman et al., 2012). The striking phenotypes of these mutants have been likened to those of homeotic mutants in which Hox genes, conferring segmental identity along the anterior-posterior axis of animal bodies, are non-functional (Meyerowitz, 2002; Sablowski, 2010). However, in contrast to Hox genes, which encode homeodomain transcription factors, most floral organ identity genes code for transcription factors of the MADS domain family (Lohmann and Weigel, 2002; Jack, 2004; Krizek and Fletcher, 2005), indicating that these functionally analogous master regulatory genes have different evolutionary origins.

Genetic and phenotypic analyses of the floral homeotic mutants led to the conclusion that the floral organ identity genes act in a combinatorial manner to control the developmental programmes required for floral organ formation (Bowman et al., 1989, 1991b, 1993). This result provided the basis for arguably the best known genetic model in the plant sciences, the ABC model of floral organ identity specification (Schwarz-Sommer et al., 1990; Bowman et al., 1991b, 1993; Coen and Meyerowitz, 1991). According to this model, the formation of sepals in Arabidopsis is controlled by the A function genes APETALA1 (AP1) and APETALA2 (AP2); 


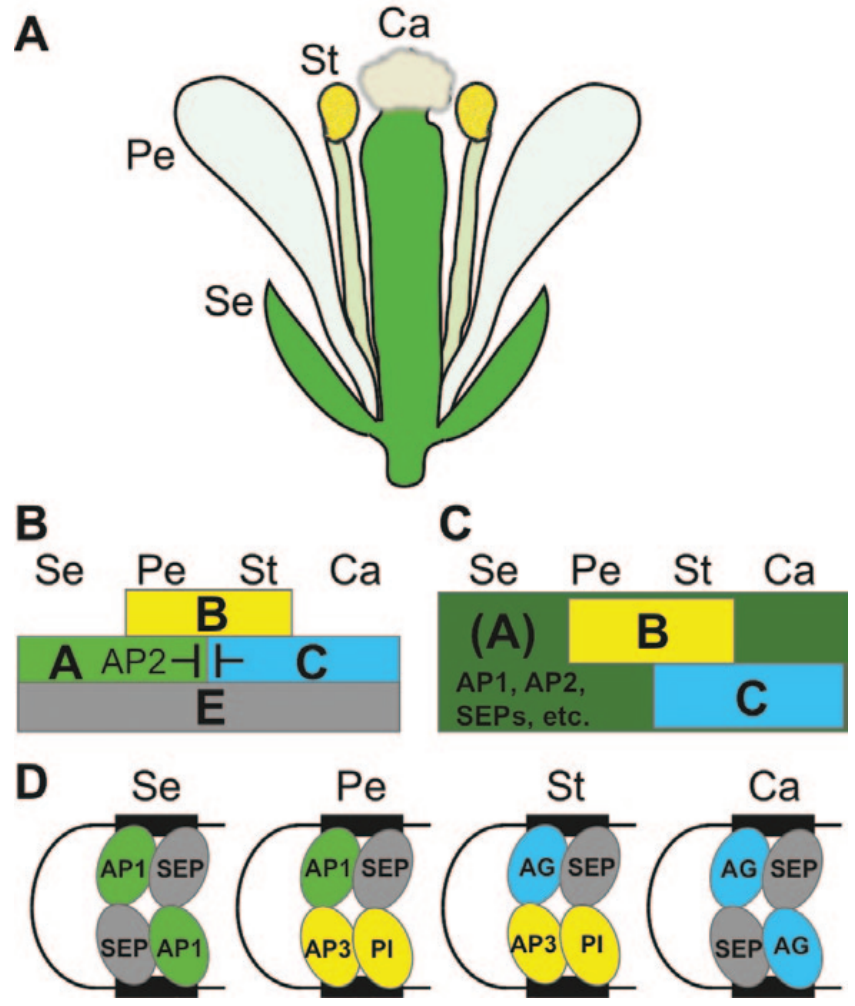

Fig. 1. Specification of floral organs by complexes of floral organ identity factors. (A) Schematic representation of an Arabidopsis flower with four types of floral organs (Se, sepal; Pe, petal; St, stamen; $\mathrm{Ca}$, carpel), which are arranged in four floral whorls. ( $B$ and $C$ ) The $A B C$ model and its modifications. (B) The ABCE model encompasses the original $A B C$ model, which posits that $A, B$, and $C$ function genes act in a combinatorial manner to specify the different types of floral organs. In addition, the ABCE model states that $E$ function is required for the formation of all organ types. (C) The (A)BC model was proposed to account for an apparent absence of $A$ function genes (as defined by the ABC model for Arabidopsis) in most angiosperms. The newly defined (A) function is thought to control floral meristem identity, as well as the activation of $\mathrm{B}$ and $\mathrm{C}$ function genes in spatially restricted domains of the floral meristem. It combines $A$ and $E$ function genes and also includes additional regulators (not shown). (D) Four different transcription factor complexes, each composed of four MADS domain proteins (as indicated), control floral organ development. These regulatory complexes are thought to bind to two CArG-box sequences (black rectangles) in the promoters of target genes, resulting in DNA bending, which may be required for transcriptional control.

petal development by the combined activities of the A function genes and the $\mathrm{B}$ function genes APETALA3 (AP3) and PISTILLATA (PI); stamen formation by the $\mathrm{B}$ function genes and the $\mathrm{C}$ function gene $A G A M O U S(A G)$; and carpel development by $\mathrm{C}$ function gene activity alone (Fig. 1B). Furthermore, it was proposed that $\mathrm{A}$ and $\mathrm{C}$ function genes act in a mutually antagonistic manner, preventing their activities from extending into each other's domain. Although the ABC model has been largely confirmed in Arabidopsis at the molecular level, it has been both refined and expanded over the years. Moreover, the general applicability of some aspects of this model has been questioned because notable differences in the control of flower development between Arabidopsis and other angiosperms have been found. In this review, we will describe some of the work that led to these conclusions and to modifications of the original ABC model. We will also discuss recent progress that resulted in detailed insights into the gene expression programmes acting downstream of the floral organ identity factors and in a better understanding of how floral organs are specified. Lastly, we will discuss open questions that need to be addressed in order to achieve a more comprehensive view of the molecular mechanisms underlying floral organ development and differentiation.

\section{Timing of floral organ specification}

Floral organ primordia emerge in a characteristic pattern from floral meristems, which themselves are derived from the inflorescence meristem. In Arabidopsis, sepal primordia are initiated first, followed by those for petals and stamens, and, lastly, carpel development is initiated in the centre of the developing flower (Smyth et al., 1990). Once carpel primordia have been formed, the stem cells present within floral meristems undergo differentiation to prevent an overgrowth of the flower. This control of meristem determinacy is accomplished by a complex network of regulatory genes, in which the $\mathrm{C}$ function gene $A G$ plays a key role (reviewed in Sun and Ito, 2010).

Floral organ primordia are thought to develop from a small number (2-8) of floral organ founder cells in the L1 (the uppermost) cell layer of the floral meristem (Bossinger and Smyth, 1996). Similar to the formation of other plant organs, the initiation and outgrowth of floral organ primordia depend on the activities of different phytohormones, and in particular, the formation of auxin concentration maxima in the regions of the floral meristem from which the primordia arise. In fact, mutants affected in genes involved in auxin biosynthesis, transport, and response often exhibit severe floral defects, including a loss of floral organs (Cheng and Zhao, 2007). Auxin also plays a key role in establishing the largely invariant arrangement of the different types of floral organs in the floral whorls. For example, it has been shown that the initiation of petals depends on the transcription factor PETAL LOSS (PTL), whose activity appears to influence auxin availability and thus the formation of auxin maxima in the perianth (Lampugnani et al., 2013). Whether auxin also drives the specification of floral organ founder cells per se is currently unknown. It has been suggested that the floral organ founder cell marker gene DORNRÖSCHEN-LIKE (DRNL) may be expressed prior to the formation of detectable auxin maxima (Chandler, 2011; Chandler et al., 2011). Thus, auxin might not be directly involved in founder cell specification. However, given the complex and dynamic interplay between auxin synthesis, transport, and response, and its functional interactions with other hormones (Vanstraelen and Benkova, 2012), it remains possible that auxin is indeed an inductive signal for floral organ formation. 
Once floral organ primordia have been initiated, expression of the floral organ identity genes is activated in the organs they help to specify through a highly complex network of regulatory genes (reviewed in O'Maoileidigh et al., 2013a). Timed activation and/or perturbation experiments of $\mathrm{B}$ and $\mathrm{C}$ function genes showed that the reproductive floral organs are specified shortly after the expression of these genes commences (Bowman et al., 1989; Ito et al., 2007; Wuest et al., 2012; O'Maoileidigh et al., 2013b). In contrast, petal fate appears to be determined considerably later, at more intermediate stages of flower development (Wuest et al., 2012), despite the fact that $\mathrm{A}$ and $\mathrm{B}$ function regulators are already expressed in incipient petal primordia. This observation correlates well with the (compared with other organ types) slow growth rate of petal primordia during early flower development (Smyth et al., 1990). However, whether this delayed development is a cause or rather a consequence of the late specification event is unknown. The timing of sepal specification has not yet been determined, but it has been suggested that sepals are the default state of floral organs (Causier et al., 2010). Thus, sepal identity might be a consequence of the specification of floral meristems through the activities of so-called floral meristem identity genes (reviewed in Wellmer and Riechmann, 2010) at the very onset of flower development.

The expression of the floral organ identity genes is not only observed during early floral stages but persists in floral organs throughout most of their development (Yanofsky et al., 1990; Bowman et al., 1991a; Jack et al., 1992; Mandel et al., 1992; Goto and Meyerowitz, 1994). This prolonged expression suggests that they control not only the specification but also the differentiation of floral organs. Indeed, through activation and/or perturbation experiments, it was shown that the floral organ identity factors regulate different processes during organ morphogenesis, including microsporogenesis, anther formation, as well as organ growth and maturation (Fig. 2) (Bowman et al., 1989; Ito et al., 2007; Wuest et al., 2012; O'Maoileidigh et al., 2013b). What is the molecular basis of the distinct functions of the floral organ identity factors during the course of flower development? While the answer to this question is still largely unknown, considerable progress has been made in recent years towards understanding the activities of these master regulators. A particularly important step in this process was the identification of the molecular mechanisms underlying the $\mathrm{ABC}$ model.

\section{The ABC model: modifications and molecular basis}

As mentioned above, the $\mathrm{ABC}$ model has been both refined and expanded since its introduction $>20$ years ago (Causier et al., 2010; Bowman et al., 2012). A main revision resulted from the identification of four SEPALLATA genes (SEP1$S E P 4$ ), which act in a partially redundant manner and are required for the activities of the $\mathrm{A}, \mathrm{B}$, and $\mathrm{C}$ function genes (Pelaz et al., 2000; Ditta et al., 2004). The SEP genes, which like most of the other floral organ identity genes encode MADS domain proteins, were incorporated into the ABC model as conferring $\mathrm{E}$ function (this naming resulted from the fact that ' $D$ function' had been previously used for genes specifying ovule identity), leading to an ABCE model (Fig. 1B). Studies of angiosperms other than Arabidopsis showed that the genetic basis of flower development is similar to that in the model plant, underlining the common evolutionary origin of flowering plants (Soltis et al., 2007). At the same time, several (often subtle) modifications to the gene networks underlying flower development have been described, as could be expected based on the considerable differences in floral architecture that are found across angiosperm species.

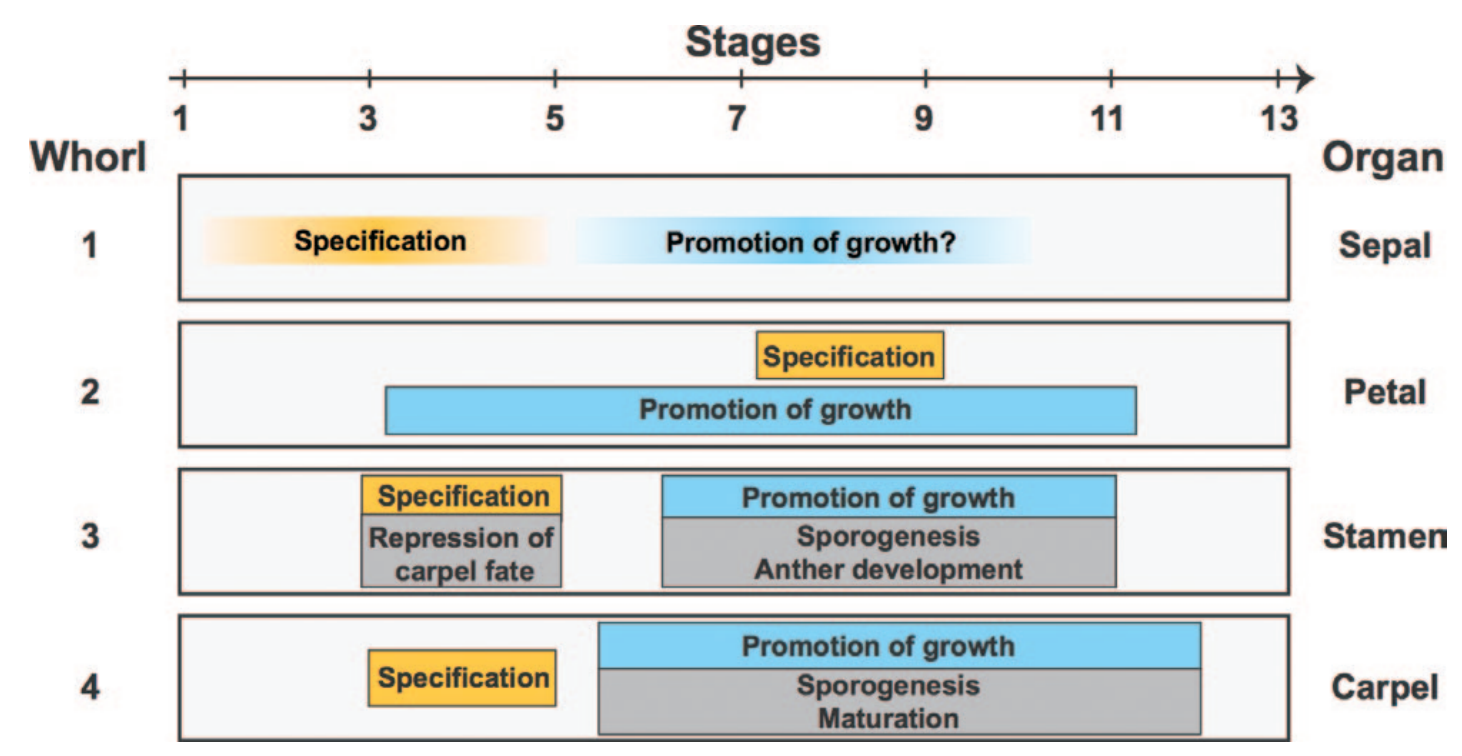

Fig. 2. Activities of the floral organ identity genes during flower development. Approximate developmental stages during which the floral organ identity genes are required for the specification, growth, and differentiation of the different types of floral organs are indicated. The floral stages during which the specification of sepals occurs are not well defined (represented by a colour gradient). Furthermore, it is unknown whether the floral organ identity genes promote sepal growth (represented by a question mark). 
A major difference between what has been described for Arabidopsis and what is found in other angiosperms, however, is the apparent absence of bona fide A function genes in many flowering plants (Litt and Kramer, 2010). This finding has led to a re-evaluation of the concept of A function and to the proposal of a modified model for floral organ identity specification, which appears more universally applicable than the original ABC model (Causier et al., 2010). This new model, termed (A)BC (Fig. 1C), is based on the idea that A as well as E function genes [referred together as '(A)' function in the revised model] are predominantly involved in specifying floral meristems, not floral organs, and mediate floral patterning by ensuring the correct expression domains of the $\mathrm{B}$ and $\mathrm{C}$ function regulators. According to this model, sepals are the default state for floral organs (see above). Hence, the fact that sepals are absent in ap1 and ap2 mutant flowers might be an indirect consequence of a failure to specify floral meristems properly. This model is supported by the results of several studies showing that $A P 1$ and $A P 2$ indeed play important roles in the specification of floral meristems (Okamuro et al., 1997; Ferrandiz et al., 2000). Furthermore, it has been shown that while AP2 represses $A G$ expression in the outer two floral whorls (thus fulfilling one of the proposed roles of $\mathrm{A}$ function in the original $\mathrm{ABC}$ model), it also suppresses the expression of the $\mathrm{B}$ function genes $A P 3$ and $P I$ (Krogan et al., 2012). AP2 is therefore, in all probability, not involved in promoting petal development (for which $\mathrm{B}$ function gene activity is essential) as predicted by the original ABC model, but instead plays a role in the patterning of floral meristems.

As described above, the floral organ identity genes (with the exception of $A P 2$, which codes for an AP2/ERF family transcription factor) encode MADS domain transcription factors. In the early 2000s, it was proposed, and later confirmed (Honma and Goto, 2001; Smaczniak et al., 2012), that these regulatory proteins act in higher order protein complexes in the control of flower development. This led to the proposal of the quartet model (Theissen, 2001), which is based on the idea that different combinations of four MADS domain proteins act together to control the developmental programmes required for the specification of the different types of floral organs (Fig. 1D). There is now ample evidence that these transcription factor complexes bind to CArG-box sequences [consensus: 5'-CC(A/T) ${ }_{6} \mathrm{GG}-3$ '] or pairs of CArG-boxes, which are brought into close spatial proximity to one another by DNA looping (Mendes et al., 2013). In fact, genomewide binding assays for several of the floral organ identity factors showed that they do bind preferentially to CArGboxes and that they have several thousand binding sites in the Arabidopsis genome (Kaufmann et al., 2009, 2010; Wuest et al., 2012; O'Maoileidigh et al., 2013b), suggesting a very large number of putative target genes. However, through the use of gene activation and perturbation assays, these studies also demonstrated that only a subset of the genes bound by the floral organ identity factors respond transcriptionally to an alteration of their activities. While it is currently unclear what exactly determines whether or not a binding event leads to a response in gene expression, it has been suggested that the presence (or absence) of additional co-factors might be required (Kaufmann et al., 2009; Dornelas et al., 2011; Wuest et al., 2012), similar to what has been described for Hox proteins in animals (Ladam and Sagerstrom, 2013). Indeed, several candidates for cofactors of MADS domain protein complexes have been identified (C. Liu et al., 2009; Simonini et al., 2012; Smaczniak et al., 2012) and their characterization promises more detailed insights into the molecular basis of floral organ identity specification.

\section{Gene expression programmes controlling floral organ development: a global view}

Until the advent of the genomics era in the early 2000s, genes acting downstream of the floral organ identity factors were identified only sporadically, mainly through the use of classic genetic and molecular biology approaches (Savidge et al., 1995; Ito et al., 1997; Sablowski and Meyerowitz, 1998). As technology advanced, a more systematic identification of genes acting downstream of the floral organ identity factors was made possible through transcriptomics approaches using both DNA microarrays and next-generation DNA sequencing (Wellmer and Riechmann, 2005). One initial line of research was based on the comparison of the gene expression profiles of flowers of floral homeotic mutants with those of corresponding wild-type flowers (Zik and Irish, 2003; Wellmer et al., 2004; Alves-Ferreira et al., 2007; Peiffer et al., 2008). These experiments resulted in the identification of hundreds of genes whose expression depends on the activity of the floral organ identity factors. Many of these transcripts showed specific or predominant expression in one of the four types of floral organs. In agreement with the increased morphological complexity of the reproductive floral organs when compared with the sterile organs of the perianth (i.e. sepals and petals), the vast majority of these transcripts were assigned to stamens and carpels, implying that highly specialized gene expression programmes underlie the formation of these organ types. One caveat of these studies was that they were typically conducted with whole inflorescences, resulting mainly in the identification of genes expressed at late stages of flower development (when flower buds are relatively large compared with early-stage floral primordia), and thus after floral organ identities have been specified. Furthermore, it remained unclear in most cases whether the identified genes are directly regulated by the floral organ identity factors or whether they act further downstream during organ differentiation.

To identify genes that are controlled by the floral organ identity factors during early flower development, several different experimental approaches were employed. With the help of a floral induction system, which allows the collection of hundreds of synchronized early-stage floral buds from a single plant (Wellmer et al., 2006), and translating ribosome affinity purification (TRAP) coupled to next-generation sequencing (TRAPSeq), hundreds of transcripts enriched in the domains of $A P 1$, $A P 3$, and $A G$ expression were identified (Jiao and Meyerowitz, 2010). Another approach for determining early response genes relied on the specific activation or perturbation of the floral organ identity factors in young flowers, again leading to the 
identification of a large number of candidate genes (GomezMena et al., 2005; Wuest et al., 2012; O'Maoileidigh et al., 2013b). To determine direct targets of the floral organ identity factors, the results from the different transcriptomics experiments were compared with those of genome-wide localization studies, which have now been conducted for all A, B, and C function regulators (Kaufmann et al., 2010; Yant et al., 2010; Wuest et al., 2012; O'Maoileidigh et al., 2013b), as well as for the E function factor SEP3 (Kaufmann et al., 2009). These analyses led to the identification of hundreds of genes, which are bound by the transcription factors and whose expression depends on their activities. These putative direct targets include many with well-established roles in flower development (see Table 1 for examples), but even more genes whose functions are unknown (at least in the context of flower development) and that await further characterization.

The comparisons of the genome-wide data sets for the different floral organ identity factors showed that the number of genes that are indirectly controlled by them is considerably larger than that of the direct targets (Wuest et al., 2012; O'Maoileidigh et al., 2013b), implying that floral organ formation must involve the activities of additional transcriptional regulators. In agreement with this idea, among the genes identified as targets of the floral organ identity factors, many were found to code for transcription factors (up to $\sim 30 \%$ : compared with a genome-wide distribution of such genes of $\sim 6 \%$ ) with roles in a multitude of cellular and developmental processes (Gomez-Mena et al., 2005; Kaufmann et al., 2010; Wuest et al., 2012; O'Maoileidigh et al., 2013b). Thus, the floral organ identity factors appear to mediate organ morphogenesis to a substantial extent by controlling the expression of other regulatory genes. One striking example of this is the gene NOZZLE/SPOROCYTELESS (NZZ/SPL), which is a key regulator of sporogenesis (Schiefthaler et al., 1999; Yang et al., 1999). NZZ/SPL is directly promoted by the B and C function regulators (Ito et al., 2004; Wuest et al., 2012; O'Maoileidigh et al., 2013b), and an ectopic activation of the gene in ag mutant flowers can induce microsporogenesis in petals (Ito et al., 2004). Thus, the NZZ/SPL transcription factor appears to mediate a central aspect of reproductive floral organ development originally attributed to the floral organ identity factors. Notably, NZZ/SPL appears to promote $A G$ expression (X. Liu et al., 2009), suggesting the presence of a positive feedback loop that ensures proper expression levels of the two master regulators.

As with $N Z Z / S P L$, several other genes were identified that are targeted by more than one of the floral organ identity factors, an observation that can be readily explained by the composition of the ternary complexes that act in flower organ development. However, in some cases, the floral organ identity factors appear to have marked antagonistic activities on target genes. Perhaps the best example of this to date are genes, such as CRABS CLAW (CRC) (Bowman and Smyth, 1999), which are involved in the control of carpel development. These genes are generally activated by AG, but suppressed by AP3/PI (Wuest et al., 2012; O'Maoileidigh et al., 2013b). It has been argued that these antagonistic activities of the $\mathrm{B}$ and $\mathrm{C}$ function regulators are crucial for the specification of stamens and carpels, because they help to separate the male from the female developmental programme. However, the molecular mechanism underlying these different activities is currently unknown and awaits further characterization.

Table 1. Examples of floral regulatory genes controlled by the floral organ identity factors AP1, AP3/PI, and AG

Whether a gene is thought to be a direct target ('Yes') or not ('No') is indicated. Arrows mark genes that are activated ( $\uparrow$ ) or repressed ( $\downarrow$ ) by a floral organ identity factor. 'Bound' indicates that a given gene's predicted regulatory region contains a binding site for a floral organ identity factor but has not (yet) been found to respond to a perturbation of its activity.

\begin{tabular}{|c|c|c|c|c|}
\hline Function & Gene name & AP1 & AP3/PI & AG \\
\hline \multirow{4}{*}{$\begin{array}{l}\text { Patterning and organ } \\
\text { specification }\end{array}$} & APETALA3 & $\operatorname{Yes}(\uparrow)$ & $\operatorname{Yes}(\uparrow)$ & $\operatorname{Yes}(\uparrow)$ \\
\hline & PISTILLATA & Yes( () & Yes $(\uparrow)$ & Bound \\
\hline & AGAMOUS & $\operatorname{Yes}(\uparrow)$ & Bound & Yes $(\uparrow)$ \\
\hline & ROXY1 & No & $\operatorname{Yes}(\uparrow)$ & Bound \\
\hline \multirow{7}{*}{$\begin{array}{l}\text { Reproductive organ } \\
\text { development }\end{array}$} & CRABS CLAW & No & $\operatorname{Yes}(\downarrow)$ & $\operatorname{Yes}(\uparrow)$ \\
\hline & SHATTERPROOF 2 & Bound & Yes $(\downarrow)$ & Yes $(\uparrow)$ \\
\hline & HECATE 1 & Bound & Yes $(\downarrow)$ & Yes( $(\uparrow)$ \\
\hline & HECATE 2 & No & Yes $(\downarrow)$ & Yes( () \\
\hline & ALCATRAZ & No & $\operatorname{Yes}(\downarrow)$ & No \\
\hline & VERDANDI & No & Yes $(\downarrow)$ & Yes $(\uparrow)$ \\
\hline & NOZZLE/SPOROCYTELESS & No & Yes $(\uparrow)$ & Yes $(\uparrow)$ \\
\hline \multirow[t]{4}{*}{ Boundary formation } & CUP-SHAPED COTYLEDON 1 & Yes( () & Yes $(\uparrow)$ & Yes( () \\
\hline & CUP-SHAPED COTYLEDON 3 & Yes $(\downarrow)$ & Yes $(\downarrow)$ & Bound \\
\hline & SUPERMAN & No & Yes $(\uparrow)$ & Yes $(\uparrow)$ \\
\hline & RABBIT EARS & No & $\operatorname{Yes}(\uparrow)$ & $\operatorname{Yes}(\downarrow)$ \\
\hline \multirow[t]{2}{*}{ Organ growth } & JAGGED & No & Bound & Yes $(\uparrow)$ \\
\hline & NUBBIN & No & No & No \\
\hline
\end{tabular}

Data are based on genome-wide analyses of floral organ identity factor function (Gomez-Mena et al., 2005; Kaufmann et al., 2010; Wuest et al., 2012; O'Maoileidigh et al., 2013b). 
As indicated above, the formation of organ primordia and the differentiation of floral organs is thought to be mediated in part by the activities of different phytohormones. The global analysis of floral organ identity factor target genes revealed that they regulate the expression of many genes involved in hormone responses and metabolism. For example, it was shown that the $\mathrm{C}$ function regulator $\mathrm{AG}$ promotes the expression of DEFECTIVE IN ANTHER DEHISCENCEI (DADl) (Ito et al., 2007). DADI encodes an enzyme involved in the synthesis of jasmonic acid, a hormone which has been shown to be important for both petal and stamen maturation (Ito et al., 2007; Brioudes et al., 2009). Similarly, AG and AP1 have been implicated in the control of genes involved in gibberellin metabolism and response (Gomez-Mena et al., 2005; Kaufmann et al., 2010), and SEP3 seems to play a role in regulating genes involved in auxin responses such as that coding for the auxin response factor ETTIN (Kaufmann et al., 2009). However, how these hormone pathways act in the control of floral organ development, and whether there is crosstalk between them, remains largely unknown.

\section{Modifying and suppressing the leaf development programme}

In the late 18th century, the polymath Johann Wolfgang von Goethe proposed in his seminal essay Die Metamorphose der Pflanzen (von Goethe, 1790) that floral organs are modified leaves. There is now ample genetic evidence in support of this conjecture: triple mutants, in which $\mathrm{A}, \mathrm{B}$, and C function activities are simultaneously affected (Bowman et al., 1991b), or plants in which all four SEP genes are nonfunctional (Ditta et al., 2004), form leaves in place of floral organs. Also, the ectopic expression of certain combinations of the floral organ identity genes results in the conversion of leaves into floral organs (Goto et al., 2001; Honma and Goto, 2001; Pelaz et al., 2001), indicating that the floral organ identity genes are not only necessary but also sufficient for floral organ formation. However, the molecular mechanisms underlying this organ transformation activity are largely unknown (Sablowski, 2010). From the transcriptomics and ChIP-Seq experiments described above, it is clear that one key function of the floral organ identity factors is the activation of specific gene sets that are required for the development of the different floral organ types. A largely unsolved question, however, is whether this new developmental programme simply over-rides an underlying programme for leaf development, or whether leaf development is actively suppressed by the floral organ identity factors. Recent results suggest that the latter may be true. It was shown the $\mathrm{B}$ and $\mathrm{C}$ function regulators inhibit the initiation of branched trichomes (a typical feature of leaves) on reproductive floral organs in part through the direct control of key regulatory genes (O'Maoileidigh et al., $2013 b$ ). However, there is also growing evidence that the floral organ identity factors not only suppress certain aspects of the leaf development programme but also 're-use' regulators of leaf development in order to specify and shape floral organs. One example of this is the gene JAGGED (JAG), a direct target of AG (Gomez-Mena et al., 2005), which controls organ formation in a partially redundant manner with its paralogue, $N U B B I N(N U B)$, by mediating the transition from meristem to primordium identity (Dinneny et al., 2004, 2006; Ohno et al., 2004; Schiessl et al., 2012; Sauret-Gueto et al., 2013). Other examples include genes involved in the specification of leaf polarity, which also contribute to floral organ morphogenesis (Wuest et al., 2012; O’Maoileidigh et al., 2013b). Thus, it appears that during the course of floral evolution the appearance of the floral organ identity genes led not only to the activation of new genes sets and to the repression of others, but also to the redeployment of regulatory genes as part of the gene network that controls flower development. Because there is little evidence for a function of MADS domain proteins in leaf development, it appears likely that this redeployment required the acquisition of functional CArG-box sequences in the promoters of these genes.

\section{Future directions}

The work discussed in this review led to detailed insights into the functions of the floral organ identity factors during floral organ specification and differentiation, and to the identification of many genes whose expression is controlled by their activities. However, in the vast majority of cases, the functions of the genes that act downstream of the floral organ identity factors are unknown. Although the powerful reverse genetics techniques available for Arabidopsis can be applied for their characterization, such work may be hampered by the high degree of functional redundancy that is thought to exist among genes involved in floral organ development (Wellmer et al., 2006). Another major shortcoming is that the positions of genes within the flowering gene network, and their possible regulatory interactions, have not been determined in the vast majority of cases. Moreover, we currently do not understand how the gene regulatory events that have been described translate into cell division patterns and the cell differentiation events that ultimately lead to the development of mature floral organs. In order to obtain indepth views into these processes, a combination of different experimental and computational approaches, including genomic technologies, live imaging, and mathematical modelling (Alvarez-Buylla et al., 2007), will probably be necessary. Furthermore, in addition to eventually connecting the gene regulatory network with the developmental biology of the cell through these approaches, it will also have to be related to its biochemistry, metabolism, and protein activities. The activities of the floral organ identity factors must also be characterized with better spatio-temporal resolution so that information about their target genes at different stages of development and in specific spatial domains, tissues, and cell types can be obtained. To this end, techniques such as the aforementioned TRAP-Seq as well as INTACT (Deal and Henikoff, 2010), which allow the isolation of transcripts and/or chromatin from specific cell types or expression domains, and laser capture microdissection (Wuest et al., 2010) should prove beneficial. This analysis of gene 
expression during floral organ formation must be further extended to the epigenetic mechanisms that contribute to the control of flower development. Another likely focus of future research will be to compare the data obtained using Arabidopsis with those from other angiosperms. As outlined above, such work has already led to the discovery of notable differences in the molecular mechanisms that govern flower formation in different species, and over time should result in a better understanding of the processes underlying the evolution of flower development. Although we are still far from having a comprehensive view of the genetics of floral organ specification and morphogenesis, the rate with which progress has been made in recent years bodes extremely well for major breakthroughs in this area of research in the near future.

\section{Acknowledgements}

Work in our laboratories is funded by grants from the Science Foundation Ireland (to EG and FW) and from the Spanish Ministerio de Economía y Competitividad (to JLR).

\section{References}

Alvarez-Buylla ER, Benitez M, Davila EB, Chaos A, EspinosaSoto C, Padilla-Longoria P. 2007. Gene regulatory network models for plant development. Current Opinion in Plant Biology 10, 83-91.

Alves-Ferreira M, Wellmer F, Banhara A, Kumar V, Riechmann JL, Meyerowitz EM. 2007. Global expression profiling applied to the analysis of Arabidopsis stamen development. Plant Physiology 145, 747-762.

Bossinger G, Smyth DR. 1996. Initiation patterns of flower and floral organ development in Arabidopsis thaliana. Development 122, 1093-1102.

Bowman JL, Alvarez J, Weigel D, Meyerowitz EM, Smyth DR. 1993. Control of flower development in Arabidopsis thaliana by APETALA1 and interacting genes. Development 119, 721-743.

Bowman JL, Drews GN, Meyerowitz EM. 1991a. Expression of the Arabidopsis floral homeotic gene AGAMOUS is restricted to specific cell types late in flower development. The Plant Cell 3, 749-758.

Bowman JL, Smyth DR. 1999. CRABS CLAW, a gene that regulates carpel and nectary development in Arabidopsis, encodes a novel protein with zinc finger and helix-loop-helix domains. Development 126, 2387-2396.

Bowman JL, Smyth DR, Meyerowitz EM. 1989. Genes directing flower development in Arabidopsis. The Plant Cell 1, 37-52.

Bowman JL, Smyth DR, Meyerowitz EM. 1991b. Genetic interactions among floral homeotic genes of Arabidopsis.

Development 112, 1-20.

Bowman JL, Smyth DR, Meyerowitz EM. 2012. The ABC model of flower development: then and now. Development 139, 4095-4098.

Brioudes F, Joly C, Szecsi J, Varaud E, Leroux J, Bellvert F, Bertrand C, Bendahmane M. 2009. Jasmonate controls late development stages of petal growth in Arabidopsis thaliana. The Plant Journal 60, 1070-1080.
Causier B, Schwarz-Sommer Z, Davies B. 2010. Floral organ identity: 20 years of ABCs. Seminars in Cell and Developmental Biology 21, 73-79.

Chandler JW. 2011. Founder cell specification. Trends in Plant Science 16, 607-613.

Chandler JW, Jacobs B, Cole M, Comelli P, Werr W. 2011. DORNROSCHEN-LIKE expression marks Arabidopsis floral organ founder cells and precedes auxin response maxima. Plant Molecular Biology 76, 171-185.

Cheng YF, Zhao YD. 2007. A role for auxin in flower development. Journal of Integrative Plant Biology 49, 99-104.

Coen ES, Meyerowitz EM. 1991. The war of the whorls: genetic interactions controlling flower development. Nature 353, 31-37.

Deal RB, Henikoff S. 2010. A simple method for gene expression and chromatin profiling of individual cell types within a tissue.

Developmental Cell 18, 1030-1040.

Dinneny JR, Weigel D, Yanofsky MF. 2006. NUBBIN and JAGGED define stamen and carpel shape in Arabidopsis. Development 133, 1645-1655.

Dinneny JR, Yadegari R, Fischer RL, Yanofsky MF, Weigel D. 2004. The role of JAGGED in shaping lateral organs. Development 131, 1101-1110.

Ditta G, Pinyopich A, Robles P, Pelaz S, Yanofsky MF. 2004. The SEP4 gene of Arabidopsis thaliana functions in floral organ and meristem identity. Current Biology 14, 1935-1940.

Dornelas MC, Patreze CM, Angenent GC, Immink RG. 2011. MADS: the missing link between identity and growth? Trends in Plant Science 16, 89-97.

Ferrandiz C, Gu Q, Martienssen R, Yanofsky MF. 2000. Redundant regulation of meristem identity and plant architecture by FRUITFULL, APETALA1 and CAULIFLOWER. Development 127, 725-734.

Gomez-Mena C, de Folter S, Costa MM, Angenent GC, Sablowski R. 2005. Transcriptional program controlled by the floral homeotic gene AGAMOUS during early organogenesis. Development 132, 429-438.

Goto K, Kyozuka J, Bowman JL. 2001. Turning floral organs into leaves, leaves into floral organs. Current Opinion in Genetics and Development 11, 449-456.

Goto K, Meyerowitz EM. 1994. Function and regulation of the Arabidopsis floral homeotic gene PISTILLATA. Genes and Development 8, 1548-1560.

Honma T, Goto K. 2001. Complexes of MADS-box proteins are sufficient to convert leaves into floral organs. Nature 409, 525-529.

Ito T, Ng KH, Lim TS, Yu H, Meyerowitz EM. 2007. The homeotic protein AGAMOUS controls late stamen development by regulating a jasmonate biosynthetic gene in Arabidopsis. The Plant Cell 19, 3516-3529.

Ito T, Takahashi N, Shimura Y, Okada K. 1997. A serine/threonine protein kinase gene isolated by an in vivo binding procedure using the Arabidopsis floral homeotic gene product, AGAMOUS. Plant and Cell Physiology 38, 248-258.

Ito T, Wellmer F, Yu H, Das P, Ito N, Alves-Ferreira M, Riechmann JL, Meyerowitz EM. 2004. The homeotic 
Page 8 of 9 | Wellmer et al.

protein AGAMOUS controls microsporogenesis by regulation of SPOROCYTELESS. Nature 430, 356-360.

Jack T, Brockman LL, Meyerowitz EM. 1992. The homeotic gene APETALA3 of Arabidopsis thaliana encodes a MADS box and is expressed in petals and stamens. Cell 68, 683-697.

Jack T. 2004. Molecular and genetic mechanisms of floral control. The Plant Cell 16 Suppl, S1-S17.

Jiao Y, Meyerowitz EM. 2010. Cell-type specific analysis of translating RNAs in developing flowers reveals new levels of control. Molecular Systems Biology 6, 419.

Kaufmann K, Muino JM, Jauregui R, Airoldi CA, Smaczniak C, Krajewski P, Angenent GC. 2009. Target genes of the MADS transcription factor SEPALLATA3: integration of developmental and hormonal pathways in the Arabidopsis flower. PLoS Biology 7, e1000090.

Kaufmann K, Wellmer F, Muino JM, et al. 2010. Orchestration of floral initiation by APETALA1. Science $\mathbf{3 2 8}$, 85-89.

Krizek BA, Fletcher JC. 2005. Molecular mechanisms of flower development: an armchair guide. Nature Reviews Genetics 6, 688-698.

Krogan NT, Hogan K, Long JA. 2012. APETALA2 negatively regulates multiple floral organ identity genes in Arabidopsis by recruiting the co-repressor TOPLESS and the histone deacetylase HDA19. Development 139, 4180-4190.

Ladam F, Sagerstrom CG. 2013. Hox regulation of transcription: more complex(es). Developmental Dynamics (in press).

Lampugnani ER, Kilinc A, Smyth DR. 2013. Auxin controls petal initiation in Arabidopsis. Development 140, 185-194.

Litt A, Kramer EM. 2010. The ABC model and the diversification of floral organ identity. Seminars in Cell and Developmental Biology 21, 129-137.

Liu C, Xi W, Shen L, Tan C, Yu H. 2009. Regulation of floral patterning by flowering time genes. Developmental Cell 16, 711-722.

Liu X, Huang J, Parameswaran S, Ito T, Seubert B, Auer M, Rymaszewski A, Jia G, Owen HA, Zhao D. 2009. The SPOROCYTELESS/NOZZLE gene is involved in controlling stamen identity in Arabidopsis. Plant Physiology 151, 1401-1411.

Lohmann JU, Weigel D. 2002. Building beauty: the genetic control of floral patterning. Developmental Cell 2, 135-142.

Mandel MA, Gustafson-Brown C, Savidge B, Yanofsky MF. 1992. Molecular characterization of the Arabidopsis floral homeotic gene APETALA1. Nature 360, 273-277.

Mendes MA, Guerra RF, Berns MC, Manzo C, Masiero S, Finzi L, Kater MM, Colombo L. 2013. MADS domain transcription factors mediate short-range DNA looping that is essential for target gene expression in Arabidopsis. The Plant Cell 25, 2560-2572.

Meyerowitz EM. 2002. Plants compared to animals: the broadest comparative study of development. Science 295, 1482-1485.

O'Maoileidigh DS, Graciet E, Wellmer F. 2013a. Gene networks controlling Arabidopsis thaliana flower development. New Phytologist (in press).

O'Maoileidigh DS, Wuest SE, Rae L, et al. 2013b. Control of reproductive floral organ identity specification in Arabidopsis by the $\mathrm{C}$ function regulator AGAMOUS. The Plant Cell 25, 2482-2503.
Ohno CK, Reddy GV, Heisler MG, Meyerowitz EM. 2004. The Arabidopsis JAGGED gene encodes a zinc finger protein that promotes leaf tissue development. Development 131, 1111-1122.

Okamuro JK, Szeto W, Lotys-Prass C, Jofuku KD. 1997. Photo and hormonal control of meristem identity in the Arabidopsis flower mutants apetala2 and apetala1. The Plant Cell 9, 37-47.

Peiffer JA, Kaushik S, Sakai H, Arteaga-Vazquez M, SanchezLeon N, Ghazal H, Vielle-Calzada JP, Meyers BC. 2008. A spatial dissection of the Arabidopsis floral transcriptome by MPSS. BMC Plant Biology 8, 43.

Pelaz S, Ditta GS, Baumann E, Wisman E, Yanofsky MF. 2000. $B$ and $C$ floral organ identity functions require SEPALLATA MADS-box genes. Nature 405, 200-203.

Pelaz S, Tapia-Lopez R, Alvarez-Buylla ER, Yanofsky MF. 2001. Conversion of leaves into petals in Arabidopsis. Current Biology 11, 182-184.

Sablowski R. 2010. Genes and functions controlled by floral organ identity genes. Seminars in Cell and Developmental Biology 21, 94-99.

Sablowski RW, Meyerowitz EM. 1998. A homolog of NO APICAL MERISTEM is an immediate target of the floral homeotic genes APETALA3/PISTILLATA. Cell 92, 93-103.

Sauret-Gueto S, SchiessI K, Bangham A, Sablowski R, Coen E. 2013. JAGGED controls Arabidopsis petal growth and shape by interacting with a divergent polarity field. PLoS Biology 11, e1001550.

Savidge B, Rounsley SD, Yanofsky MF. 1995. Temporal relationship between the transcription of two Arabidopsis MADS box genes and the floral organ identity genes. The Plant Cell 7, 721-733.

Schiefthaler U, Balasubramanian S, Sieber P, Chevalier D, Wisman E, Schneitz K. 1999. Molecular analysis of NOZZLE, a gene involved in pattern formation and early sporogenesis during sex organ development in Arabidopsis thaliana. Proceedings of the National Academy of Sciences, USA 96, 11664-11669.

SchiessI K, Kausika S, Southam P, Bush M, Sablowski R. 2012. JAGGED controls growth anisotropy and coordination between cell size and cell cycle during plant organogenesis. Current Biology 22, 1739-1746.

Schwarz-Sommer Z, Huijser P, Nacken W, Saedler H, Sommer H. 1990. Genetic control of flower development by homeotic genes in Antirrhinum majus. Science 250, 931-936.

Simonini S, Roig-Villanova I, Gregis V, Colombo B, Colombo L, Kater MM. 2012. Basic pentacysteine proteins mediate MADS domain complex binding to the DNA for tissue-specific expression of target genes in Arabidopsis. The Plant Cell 24, 4163-4172.

Smaczniak C, Immink RG, Muino JM, et al. 2012. Characterization of MADS-domain transcription factor complexes in Arabidopsis flower development. Proceedings of the National Academy of Sciences, USA 109, 1560-1565.

Smyth DR, Bowman JL, Meyerowitz EM. 1990. Early flower development in Arabidopsis. The Plant Cell 2, 755-767.

Soltis DE, Chanderbali AS, Kim S, Buzgo M, Soltis PS. 2007. The ABC model and its applicability to basal angiosperms. Annals of Botany 100, 155-163. 
Sun B, Ito T. 2010. Floral stem cells: from dynamic balance towards termination. Biochemical Society Transactions 38, 613-616.

Theissen G. 2001. Development of floral organ identity: stories from the MADS house. Current Opinion in Plant Biology 4, 75-85.

Vanstraelen M, Benkova E. 2012. Hormonal interactions in the regulation of plant development. Annual Review of Cell and Developmental Biology 28, 463-487.

von Goethe JW. 1790. Versuch die Metamorphose der Pflanzen zu erklären . Gotha, Germany: Ettinger.

Wellmer F, Riechmann JL, Alves-Ferreira M, Meyerowitz

EM. 2004. Genome-wide analysis of spatial gene expression in Arabidopsis flowers. The Plant Cell 16, 1314-1326.

Wellmer F, Riechmann JL. 2005. Gene network analysis in plant development by genomic technologies. International Journal of Developmental Biology 49, 745-759.

Wellmer F, Alves-Ferreira M, Dubois A, Riechmann JL, Meyerowitz EM. 2006. Genome-wide analysis of gene expression during early Arabidopsis flower development. PLoS Genetics 2, e117.

Wellmer F, Riechmann JL. 2010. Gene networks controlling the initiation of flower development. Trends in Genetics 26, 519-527.

Wuest SE, O'Maoileidigh DS, Rae L, Kwasniewska K, Raganelli A, Hanczaryk K, Lohan AJ, Loftus B, Graciet E, Wellmer F. 2012.
Molecular basis for the specification of floral organs by APETALA3 and PISTILLATA. Proceedings of the National Academy of Sciences, USA 109, 13452-13457.

Wuest SE, Vijverberg K, Schmidt A, Weiss M, Gheyselinck J, Lohr M, Wellmer F, Rahnenfuhrer J, von Mering C, Grossniklaus U. 2010. Arabidopsis female gametophyte gene expression map reveals similarities between plant and animal gametes. Current Biology 20, 506-512.

Yang WC, Ye D, Xu J, Sundaresan V. 1999. The SPOROCYTELESS gene of Arabidopsis is required for initiation of sporogenesis and encodes a novel nuclear protein. Genes and Development 13, 2108-2117.

Yanofsky MF, Ma H, Bowman JL, Drews GN, Feldmann KA, Meyerowitz EM. 1990. The protein encoded by the Arabidopsis homeotic gene agamous resembles transcription factors. Nature $\mathbf{3 4 6}$, 35-39.

Yant L, Mathieu J, Dinh TT, Ott F, Lanz C, Wollmann H, Chen X, Schmid M. 2010. Orchestration of the floral transition and floral development in Arabidopsis by the bifunctional transcription factor APETALA2. The Plant Cell 22, 2156-2170.

Zik M, Irish VF. 2003. Global identification of target genes regulated by APETALA3 and PISTILLATA floral homeotic gene action. The Plant Cell 15, 207-222. 